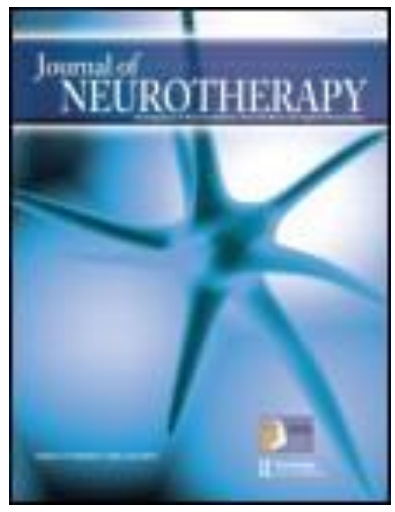

Journal of Neurotherapy: Investigations in Neuromodulation, Neurofeedback and Applied Neuroscience

\title{
The Effects of Performance Enhancement Training on Hypertension, Human Attention, Stress, and Brain Wave Patterns
}

S. Louise Norris PhD ${ }^{a}$, Ching-Tse Lee PhD ${ }^{b}$, Dmitry Burshteyn PhD ${ }^{c}$ \& Juan Cea-Aravena $M A$ d a

${ }^{a}$ Mid-Hudson Medical Psychotherapy Center, Warwick, New York, USA

b Brooklyn College, City University, New York, USA

C Siena College, New York, USA

d Laboratory of Neurofeedback and Behavioral Medicine, Brooklyn College, Warwick, New York, USA

Published online: 20 Oct 2008

To cite this article: S. Louise Norris PhD , Ching-Tse Lee PhD, Dmitry Burshteyn PhD \& Juan Cea-Aravena MA (2000) The Effects of Performance Enhancement Training on Hypertension, Human Attention, Stress, and Brain Wave Patterns, Journal of Neurotherapy: Investigations in Neuromodulation, Neurofeedback and Applied Neuroscience, 4:3, 29-44, DOI: 10.1300/J184v04n03_03

To link to this article: http://dx.doi.org/10.1300/J184v04n03_03

\section{PLEASE SCROLL DOWN FOR ARTICLE}

(c) International Society for Neurofeedback and Research (ISNR), all rights reserved. This article (the "Article") may be accessed online from ISNR at no charge. The Article may be viewed online, stored in electronic or physical form, or archived for research, teaching, and private study purposes. The Article may be archived in public libraries or university libraries at the direction of said public library or university library. Any other reproduction of the Article for redistribution, sale, resale, loan, sublicensing, systematic supply, or other distribution, including both physical and electronic reproduction for such purposes, is expressly forbidden. Preparing or reproducing derivative works of this article is expressly forbidden. ISNR makes no representation or warranty as to the accuracy or completeness of any content in the Article. From 1995 to 2013 the Journal of Neurotherapy was the official publication of ISNR (www. Isnr.org); on April 27, 2016 ISNR acquired the journal from Taylor \& Francis Group, LLC. In 2014, ISNR established its official open-access journal NeuroRegulation (ISSN: 2373-0587; www.neuroregulation.org).

\section{THIS OPEN-ACCESS CONTENT MADE POSSIBLE BY THESE GENEROUS SPONSORS}
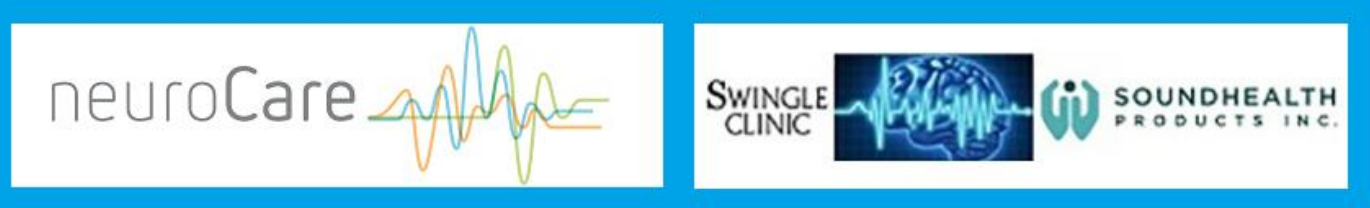

Brain/Master Technologies, Inc.

unvmonnmonnminum

From the decade of the brain into the new millenium

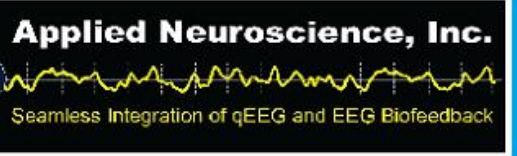




\title{
The Effects \\ of Performance Enhancement Training on Hypertension, Human Attention, Stress, and Brain Wave Patterns: A Case Study
}

\author{
S. Louise Norris, $\mathrm{PhD}$ \\ Ching-Tse Lee, $\mathrm{PhD}$ \\ Dmitry Burshteyn, PhD \\ Juan Cea-Aravena, MA
}

\begin{abstract}
Background: The purpose of this study was to evaluate the effects of alpha-increase neurofeedback training (Performance Enhancement Training) on blood pressure, stress reduction, attention, and observe changes in brainwave patterns. A forty-nine-year-old male college student diagnosed with essential hypertension controlled by medi-
\end{abstract}

S. Louise Norris is a licensed psychologist and Clinical Director of Mid-Hudson Medical Psychotherapy Center in Warwick, New York. Her practice focuses primarily in the area of neuropsychology. Dr. Norris is on staff at St. Anthony's Hospital in Warwick and a member of the Traumatic Brain Injury Advisory Board for Horton Hospital in Middletown.

Ching-Tse Lee is Professor of Psychology at Brooklyn College, City University of New York. He is a member of the Executive Committee of the Experimental Psychology Subprogram at the CUNY Graduate Center. His research interests include applied psychophysiology, biofeedback, and behavioral medicine.

Dmitry Burshteyn is Professor of Psychology at Siena College, New York. His research interests include cognitive neuroscience, performance enhancement training, neurofeedback, and applied psychophysiology.

Juan Cea-Aravena is Research Associate at the Laboratory of Neurofeedback and Behavioral Medicine, Brooklyn College and Neurofeedback Practitioner at MidHudson Medical Psychotherapy Center in Warwick, New York.

Address correspondence to: Dr. Ching-Tse Lee, Department of Psychology, Brooklyn College, 2900 Bedford Avenue, Brooklyn, NY 11210.

Journal of Neurotherapy, Vol. 4(3) 2000

Copyright (C) 2000 ISNR. All rights reserved. 
cation had undergone twenty-six sessions of alpha-increase biofeedback $(8-13 \mathrm{~Hz})$ at PZ electrode site for a period of 15 weeks.

Method: Pre- and post-blood pressure measurements were taken for every session. At the beginning of week number eight, the participant discontinued his medication as advised by his physician. Pre- and postvisual TOVA CPT test was administered to assess the changes in accuracy, reaction time (RT), and RT variability. Osterkamp and Press SelfAssessment Stress Inventory was administered before and after training to assess the level of stress. QEEG evaluation was conducted prior, as well as upon completion of the study.

Results: Mean Arterial Blood Pressure (MAP) yielded statistically significant results between pre- and post-sessions within participant blood pressure measurements. The participant's systolic and diastolic blood pressures during the first thirteen sessions were not significantly different from those of the last thirteen sessions when his medication was discontinued, suggesting his ability to control his blood pressure within normal limits without the use of medication. The results of the TOVA test clearly indicate an improvement in individuals' reaction time and the reaction time variability. The results of the Osterkamp and Press Self-Assessment Stress Inventory indicated an improvement in two of the scales: Work and Social Life. Statistical analysis showed that before and after QEEG evaluations were within normal limits.

Discussion: The mechanism through which Performance Enhancement Training simultaneously affects blood pressure, reaction time (RT), and variability needs further investigation. However, the positive changes in the measured variables appear to be a function of enhanced self-awareness that leads to the improved self-regulation.

KEYWORDS. Neurofeedback, hypertension, stress, human attention.

\section{INTRODUCTION}

Biofeedback training offers instrumental and methodological aids to learning a set of skills, which emphasize the interaction of mental, emotional, and physiological processes (Parks, 1996). A primary goal of psychophysiological self-regulation training includes development of direct perception of internal events. This perception can be learned through psychophysiological selfawareness training. Once basic self-awareness skills are developed with the assistance of biofeedback equipment, an individual might become conscious- 
ly aware of thoughts and emotions as they trigger physiologic reactions (Parks, 1997). Self-regulation training strategies are introduced by teaching sensorial awareness of physiological processes that usually occur without conscious awareness. Such training procedures have been reported to promote an internal exploration, which is believed to have a potential for leading to conscious awareness of normally unconscious mental, emotional, and physiological processes. From a theoretical perspective, conscious awareness of psychophysiological processes provides an opportunity for one to coordinate those processes. Such mind-body coordination skills might provide useful tools in an effort to promote the harmonious integration of conscious and unconscious processes (Parks, 1996).

How can these tools and techniques be used as extensions of self-awareness? One way that tools and techniques can become extensions of selfawareness is when they reveal existentially relevant, normally unconscious information to the individual whose state of consciousness is being studied. Brain wave frequencies and amplitudes are objective indicators that have substantial bearing upon subjective states of consciousness. It has been suggested that with the use of neurofeedback training strategies, individuals can learn to modify their state of consciousness by learning to modify their EEG frequencies and amplitude (Parks, 1996). Alpha-increase training has been associated with an experiential state of calmness and deep relaxation (Green \& Green, 1977).

Increasing alpha $(8-13 \mathrm{~Hz})$ EEG amplitude has been shown to play an important role in eliciting the relaxation response, which is characterized by a decrease in heart rate and blood pressure (Benson, 1975). It has been convincingly shown that the regular inappropriate activation of the fight-or-flight response might lead to such diseases as hypertension with its often deadly consequence of heart attack and stroke. Because the relaxation response counteracts the arousal of the fight-or-flight response, it is reasonable to expect that the regular evocation of the relaxation response might lead to lower blood pressure in patients who already have high blood pressure (Benson, 1975). Benson also realized that his patients were able to decrease their blood pressure by thinking relaxing thoughts. The relaxation response serves as a natural way to counteract increased sympathetic nervous system activity associated with the fight-or-flight response. This means that the relaxation response should be useful in alleviating other disease states where increased sympathetic nervous system activity is a principle factor in the development of the disease or is an undesirable accompanying factor of that disease.

Benson (1975) hypothesized that the relaxation response decreases and counteracts the increased sympathetic nervous system activity that accompanies the arousal of the fight-or-flight response. This sympathetic nervous system activity is reflected in the measures of oxygen consumption, heart 
rate, respiratory rate, and blood pressure, which increase with the fight-orflight response and decrease with the elicitation of the relaxation response (Benson, 1975, Wallace \& Benson, 1972).

Two major ways to control blood pressure that seem to be equally effective are: providing the subject with information about his blood pressure (Benson, Shapiro, Tursky \& Schwartz, 1971) or using indirect blood pressure biofeedback methodologies (Patel, 1977). Patel carried out randomized controlled trials using feedback procedures to normalize blood pressure in patients. She did not teach the patients to control the blood pressure directly through the blood-pressure-biofeedback procedure, but instead, relaxation training was used. Sixteen out of her twenty patients showed a significant reduction in mean arterial pressure and a significant reduction in medication usage.

In our view, the best non-invasive indirect blood pressure measure that provides robust blood pressure information is the average pressure difference between systolic and diastolic blood pressure during the cardiac cycle. This difference is called the Mean Arterial Pressure (MAP), and it reflects the average effective pressure that drives the blood through the circulatory system (Papillo \& Shapiro, 1990). No studies have been conducted to date investigating the relationship between EEG biofeedback training and changes in blood pressure.

Can one expect that learning to self-regulate a visceral response will also affect self-regulatory mechanisms of other cognitive functions? The increasing interest in this issue shifted the focus of the applied psychophysiology field from conditioning of visceral responses to self-regulation of attention (Fehmi, 1980). Alpha-increase EEG training has been implicated in improvement of attention (Norris, Lee, Cea \& Burshteyn, 1998). Attempts to train subjects to increase the level of alpha activity with operant conditioning began in the 1960s with Kamiya's work (1969). In their 1970 article, Nowles and Kamiya indicated that subjects could establish operant control of the alpha brain waves by increasing and decreasing alpha amplitude. Also, subjects reported general relaxation and overall pleasant sensations as a result of the generation of alpha rhythm. Ray and Cole (1985) emphasized the role of alpha waves as being an internal focus of attention. Crawford (1995) found that subjects who produce a higher percentage of alpha $(10-13 \mathrm{~Hz})$ performed better on sustained attention tasks. These findings point toward the importance of an increase in alpha percentage and consequent decrease in proportion of other waves, such as theta, in order to sustain attention.

The ability of a person to sustain attention can be measured accurately by a number of continuous performance tests. Greenberg and Waldman (1993) demonstrated that the Test of Variables of Attention (TOVA) is an objective and standardized continuous performance test used to assess attention. It is a 
nonverbal test that requires no left-right discrimination or sequencing and has no appreciable practice effects (Greenberg \& Kindschi, 1996).

In this study, we propose the existence of a double-feedback loop with multiplicative interactions where increased self-awareness is associated with increased alpha production and increased alpha production is associated with further increased self-awareness. We hypothesize that increased alpha will assist our subject in the process of enhancing his self-awareness, and his increased self-awareness will help him to become aware of stressors that trigger sympathetic reaction leading to the increase in his blood pressure. In parallel, alpha production will elicit a relaxation response that will further aid him in controlling his blood pressure. We also expect that similarly to our previous study (Norris, Lee, Cea \& Burshtyn, 1998) alpha training at the PZ electrode site will result in modification of attentional properties and lead to the subject's improvement on tasks measuring variables of attention. The purpose of our study was to evaluate the effect of Performance Enhancement Training on blood pressure, variables of attention, stress, brain wave patterns and self-awareness.

\section{METHOD}

Participant. The participant was a forty-nine-year-old white male who is currently a graduate student at one of the New York City colleges and is a member of the New York City Fire Department. He participated in this study as a volunteer and had no previous history of EEG biofeedback training. He suffered from Mild Essential Hypertension and was taking medication Loten$\sin$ (benazopril), $10 \mathrm{mg} /$ per day for his condition. Halfway through the training he discontinued his medication with the consent of his physician who observed a decrease in the participant's blood pressure.

Materials. All sessions were conducted in the sound-isolated room. The Performance Enhancement Training was conducted using a Lexicor POD-2 device. The POD-2 system software is a DOS based program. In this system the sampling rate is set to $128 \mathrm{~Hz}$ and the raw EEG is amplified at a gain of 8,000 . The filtering is accomplished in the software. The signals passed are between $.5 \mathrm{~Hz}$ (high pass filter) and $32.0 \mathrm{~Hz}$ (low pass filter). These signals are then subjected to a digital transformation that outputs spectral magnitude in microvolts as a function of frequency in the following bands: $0.5 \mathrm{~Hz}$ to 4.0 $\mathrm{Hz}$ (delta), 4.0 Hz to $8.0 \mathrm{~Hz}$ (theta), $8.0 \mathrm{~Hz}$ to $13.0 \mathrm{~Hz}$ (alpha), $10.0 \mathrm{~Hz}$ to 13.0 $\mathrm{Hz}$ (high alpha), $13.0 \mathrm{~Hz}$ to $15.0 \mathrm{~Hz}$ (SMR) and $16.0 \mathrm{~Hz}$ to $22.0 \mathrm{~Hz}$ (beta).

The pre- and post-visual TOVA continuous performance test was used to assess variables of attention. QEEG evaluation was conducted using a Lexicor Neurosearch-24 brain wave acquisition unit. The Osterkamp and Press Self-Assessment Stress Inventory was used to assess the levels of stress. The 
A\&D Engineering, Inc. Digital Blood Pressure Meter (Model \# UA-701) was used to record the participant's blood pressure before and after each session.

Procedure. The participant's blood pressure was recorded before and after each training session conducted at about the same time of the day. Mean arterial pressure (MAP) was calculated for each pre- and post-session record. MAP was measured by the following equation: $\mathrm{MAP}=1 / 3$ (SBP-DBP) DBP, where SBP is systolic and DBP is a diastolic blood pressure (Papillo \& Shapiro, 1990).

The TOVA test was administrated twice at about the same time of the day. The first administration occurred on the first day of the training, before the beginning of the first session of alpha-increase training and the second administration occurred a day after the conclusion of the twenty-six alpha-increase sessions. Prior to the initiation of the training, the participant was advised that biofeedback would be used to increase his alpha amplitude. Similar to the TOVA, the participant was administered a pre- and post-Osterkamp and Press Self-Assessment Stress Inventory. QEEG evaluations utilizing nineteen electrode sites were conducted before and after the training to compare the brainwave activity of the subject to those of the normative group.

The participant was given twenty-six thirty-minute neurofeedback sessions over a period of fifteen weeks. In addition to that, two more training sessions were recorded: the first and the last neurofeedback sessions were conducted without any feedback. The Standard International (10-20) Electrode Placement System was used to determine electrode placement. Based on this system, four electrodes were placed at the following locations: one at MidParietal (PZ), one at Fpz-ground (G), and one at each earlobe for reference. Recording did not begin until impedances were reduced to $5 \mathrm{kOhms}$ or less. Before the beginning of each session a five-minute baseline reading of alpha amplitude was recorded. The individual threshold for each session was established according to the outcome of five-minute baseline. The threshold was set at eighty-five percent of the alpha baseline value for each session. Feedback was contingent upon the presence of Alpha $(8-13 \mathrm{~Hz})$ activity.

The participant received both auditory and visual feedback. When the participant surpassed the threshold level, he was given a flute-sound as an auditory feedback and a blue bar graph exceeding the threshold line appeared on the computer screen as a visual feedback. At the end of each session the participant's statements on his subjective experience of the session were recorded.

Upon completion of twenty-six sessions, the participant was asked to demonstrate his ability to increase alpha amplitude at the experimenter's request without feedback. 


\section{RESULTS}

After twenty-six sessions of alpha-increase training at PZ, the participant exhibited an increase in average session amplitude for alpha frequency from $18.8 \mu \mathrm{V}$ in the initial session to $23.8 \mu \mathrm{V}$ in the last session (see Table 1 and Figure 1).

The participant demonstrated his ability to increase alpha wave amplitude at will in the feedback-absent condition. The results of before and after QEEG evaluations were within normal limits, as defined by Thatcher's (1999) database.

A series of t-tests for dependent measures was calculated to evaluate the changes in the Mean Arterial Pressure (MAP) before and after the training with and without medication (see Table 2 and Figure 2).

TABLE 1. Twenty-six session end average amplitudes $(\mu \mathrm{V})$ for delta, theta, alpha, high alpha, SMR, and beta brain waves collected from one participant over the 15-week period.

\begin{tabular}{|c|c|c|c|c|c|c|}
\hline \multirow{3}{*}{ Session } & \multicolumn{6}{|c|}{ Brain Waves } \\
\cline { 2 - 7 } & $\begin{array}{c}\text { Delta } \\
(0.5-4 \mathrm{~Hz})\end{array}$ & $\begin{array}{c}\text { Theta } \\
(4-8 \mathrm{~Hz})\end{array}$ & $\begin{array}{c}\text { Alpha } \\
(8-13 \mathrm{~Hz})\end{array}$ & $\begin{array}{c}\text { H Alpha } \\
(10-13 \mathrm{~Hz})\end{array}$ & $\begin{array}{c}\text { SMR } \\
(13-15 \mathrm{HZ})\end{array}$ & $\begin{array}{c}\text { Beta } \\
(16-22 \mathrm{~Hz})\end{array}$ \\
\hline 1 & 19.5 & 10.8 & 18.8 & 15.7 & 8.5 & 6.1 \\
2 & 16.7 & 10.4 & 17.4 & 14.5 & 7.5 & 5.6 \\
3 & 15.2 & 10.9 & 19.5 & 16.1 & 7.9 & 5.7 \\
4 & 16.6 & 10.8 & 18.6 & 15.6 & 7.9 & 5.9 \\
5 & 17.3 & 10.4 & 18.9 & 16.1 & 8.3 & 5.9 \\
6 & 17.6 & 11.2 & 20.1 & 17.1 & 9 & 6.4 \\
7 & 16.8 & 10.4 & 18.6 & 15.7 & 8.1 & 6 \\
8 & 16.5 & 10.1 & 19.2 & 16.9 & 8.7 & 5.8 \\
9 & 16.3 & 9.6 & 17.8 & 15.4 & 7.4 & 5.3 \\
10 & 17 & 10.2 & 19.5 & 16.9 & 8 & 5.7 \\
11 & 16.4 & 10 & 18.5 & 15.8 & 8.1 & 5.9 \\
12 & 17.3 & 10.6 & 20.5 & 17.5 & 8.4 & 6.1 \\
13 & 18.6 & 10.2 & 18.9 & 16.2 & 7.8 & 5.9 \\
14 & 17 & 9.6 & 18.8 & 15.8 & 7.1 & 5.4 \\
15 & 19.7 & 10.5 & 19 & 15.9 & 7.5 & 5.5 \\
16 & 19.2 & 10.3 & 18.6 & 16 & 7.4 & 5.6 \\
17 & 16.2 & 9.2 & 18.8 & 15.9 & 6.9 & 5.3 \\
18 & 22.1 & 11.8 & 22 & 18.3 & 7.8 & 5.7 \\
19 & 18.1 & 10 & 17.8 & 15.3 & 7.3 & 5.7 \\
20 & 18.3 & 11 & 19.6 & 16.6 & 7.4 & 5.4 \\
21 & 15.1 & 10.4 & 21.2 & 18 & 7.2 & 5.5 \\
22 & 18.4 & 11.6 & 24.2 & 20.5 & 8.3 & 6.3 \\
23 & 17 & 10.4 & 20.7 & 17.4 & 7.1 & 5.2 \\
24 & 21.9 & 10.9 & 23.8 & 20.3 & 8.1 & 5.7 \\
25 & 18.5 & 10.9 & 22.6 & 19.4 & 8.3 & 5.9 \\
26 & 18.6 & 11.7 & 23.8 & 20.2 & 8.4 & 6 \\
\hline
\end{tabular}


FIGURE 1. Twenty-six session end average amplitude for delta, theta, alpha, SMR, and beta brain waves collected from one participant over the 15-week period

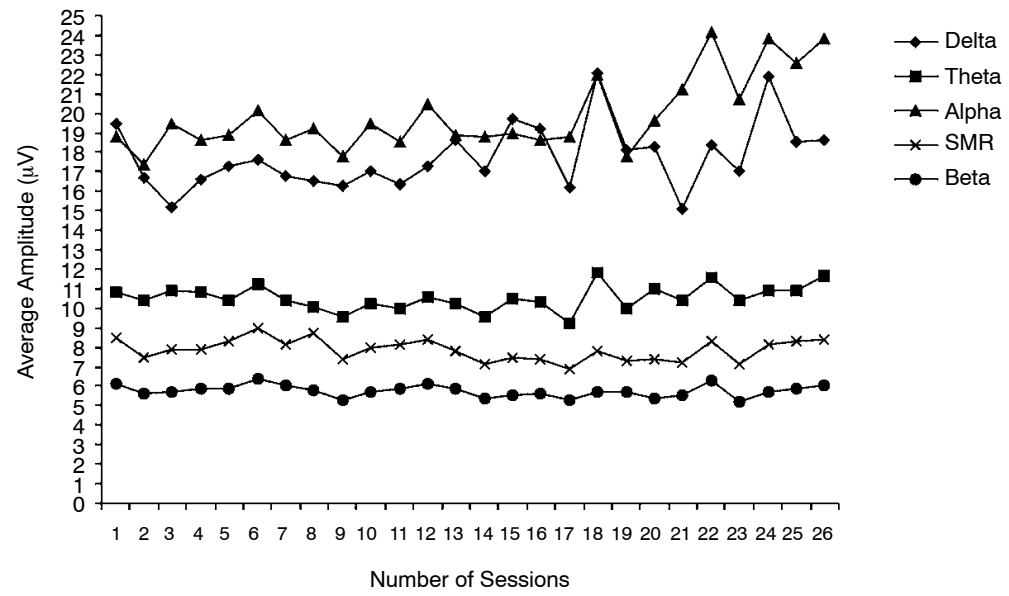

The following was established:

I. Pre- and post-training MAP resulted in a $t(27)=-2.781 p<.01$, which indicated a statistically significant decrease in blood pressure as a result of performance enhancement training.

II. In his last fourteen sessions the subject was able to maintain his systolic and diastolic blood pressure within normal limits without taking any medication as indicated by no statistically significant changes in:

1. Pre-sessions systolic blood pressure measure comparing first fourteen sessions and last fourteen sessions: $t(13)=-1.064 p<.307$.

2. Post-sessions systolic blood pressure measure comparing first fourteen sessions and last fourteen sessions: $t(13)=-2.000 p<.067$.

3. Pre-sessions diastolic blood pressure measure comparing first fourteen sessions and last fourteen sessions: $t(13)=-1.255 p<.232$.

4. Post-sessions diastolic blood pressure measure comparing first fourteen sessions and last fourteen sessions: $t(13)=-1.604, p<.133$.

The results of the pre- and post-visual TOVA test (Figures 3 and 4) indicated that the participant appreciably improved his scores in response time (RT) and response time variability (RTV) measures of attention. His total RT decreased from $398 \mathrm{msec}$ in the pre-test to $359 \mathrm{msec}$ in the post-test, a difference of $49 \mathrm{msec}$, while his RTV decreased from $100 \mathrm{msec}$ on the pre-test to $76 \mathrm{msec}$ on the post-test, a difference of $34 \mathrm{msec}$. No changes were observed for omission and commission errors. 
FIGURE 2. Mean Arterial Pressure (MAP) collected from one participant before and after twenty-six Performance Enhancement Training sessions, and on initial and final session without feedback.

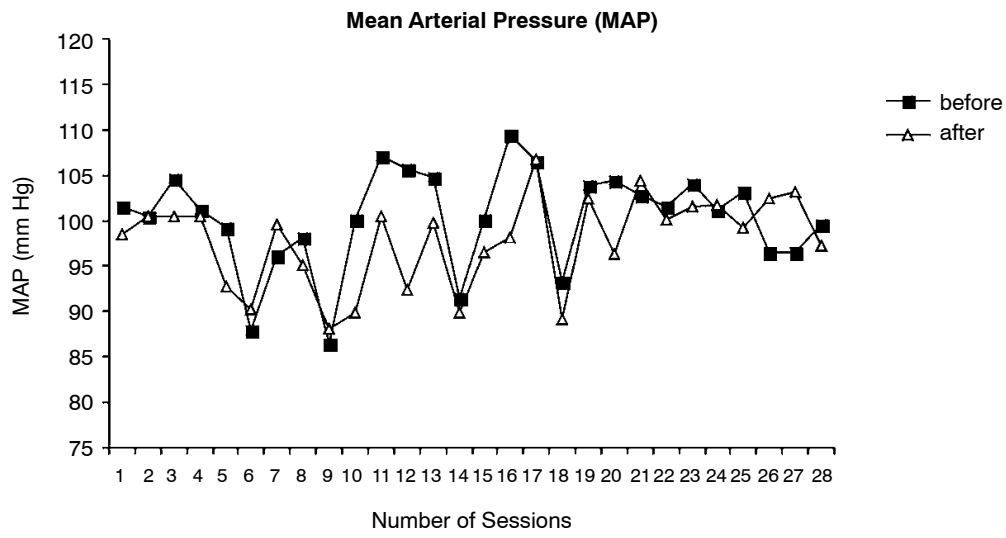

Note that last 14 sessions represent participant's blood pressure level without medication

The results of the Self-Assessment Stress Inventory suggest that the participant improved his score on the Work Scale (WS) and Social Life Scale (SLS). When asked about his ability to deal with demands from several sources at once, the participant reported feeling overwhelmed, tense, and unable to set up his priorities calmly on a pre-test and reported the absence of all of these factors on a post-test (WS). The SLS results indicate a pre- to post-change from feeling anxious, confused, and getting angry and defensive when expressing an unpopular opinion in a social gathering to their opposites.

The participant's final written self-report (Appendix) suggests an increase in his self-awareness. As a result of the training, the participant was able to recognize several major stressors that were negatively influencing his psychophysiological state. Consequently, the participant was able to modify his behavior to cope with these stressors.

\section{DISCUSSION}

During the introductory neurofeedback session the participant reported taking $10 \mathrm{mg}$ of Lotensin (benazopril), blood pressure medication, once a day for a period of one year. His physician prescribed this dosage when his systolic and diastolic blood pressure level reached 160/100 mm Hg. Through- 
TABLE 2. Twenty-eight session value for the mean arterial, systolic and diastolic blood pressures $(\mathrm{mm} \mathrm{Hg})$ collected before and after each training session and on the initial and final session without biofeedback.

\begin{tabular}{|c|c|c|c|c|c|c|}
\hline \multirow{2}{*}{ Session } & \multicolumn{3}{|c|}{ Before Session } & \multicolumn{3}{|c|}{ After Session } \\
\hline & MAP & Systolic BP & Diastolic BP & MAP & Systolic BP & Diastolic BP \\
\hline 1 & 101.49 & 137 & 84 & 98.5 & 132 & 82 \\
\hline 2 & 100.48 & 138 & 82 & 100.48 & 138 & 82 \\
\hline 3 & 104.51 & 136 & 89 & 100.51 & 132 & 85 \\
\hline 4 & 101.16 & 136 & 84 & 100.48 & 138 & 82 \\
\hline 5 & 99.14 & 138 & 80 & 92.78 & 137 & 71 \\
\hline 6 & 87.83 & 122 & 71 & 90.15 & 127 & 72 \\
\hline 7 & 96.12 & 139 & 75 & 99.52 & 129 & 85 \\
\hline 8 & 98.15 & 135 & 80 & 95.12 & 138 & 74 \\
\hline 9 & 86.49 & 122 & 69 & 88.15 & 125 & 70 \\
\hline 10 & 100.15 & 137 & 82 & 89.8 & 130 & 70 \\
\hline 11 & 107.14 & 146 & 88 & 100.41 & 152 & 75 \\
\hline 12 & 105.73 & 160 & 79 & 92.31 & 139 & 69 \\
\hline 13 & 104.8 & 145 & 85 & 99.8 & 140 & 80 \\
\hline 14 & 91.5 & 125 & 75 & 89.84 & 122 & 74 \\
\hline 15 & 100.16 & 135 & 83 & 96.45 & 140 & 75 \\
\hline 16 & 109.43 & 157 & 86 & 98.13 & 139 & 78 \\
\hline 17 & 106.48 & 144 & 88 & 106.75 & 157 & 82 \\
\hline 18 & 93.2 & 120 & 80 & 89.2 & 120 & 76 \\
\hline 19 & 103.8 & 144 & 84 & 102.43 & 150 & 79 \\
\hline 20 & 104.41 & 156 & 79 & 96.4 & 150 & 70 \\
\hline 21 & 102.77 & 149 & 80 & 104.44 & 150 & 82 \\
\hline 22 & 101.47 & 141 & 82 & 100.14 & 139 & 81 \\
\hline 23 & 104.08 & 155 & 79 & 101.48 & 138 & 82 \\
\hline 24 & 101.11 & 146 & 79 & 101.74 & 154 & 76 \\
\hline 25 & 103.14 & 142 & 84 & 99.14 & 138 & 80 \\
\hline 26 & 96.45 & 140 & 75 & 102.46 & 144 & 82 \\
\hline 27 & 96.55 & 120 & 85 & 103.19 & 132 & 89 \\
\hline 28 & 99.48 & 137 & 81 & 97.16 & 132 & 80 \\
\hline
\end{tabular}

out the training he was closely observed by his physician, and during one of the visits, which coincided with 15 th session, blood pressure medication was discontinued by his physician. The statistical analysis indicated no significant difference between his mean arterial blood pressure with and without medication, indicating his ability to maintain blood pressure levels recommended by his physician without medication. Our results indicated a significant decrease in mean arterial pressure before and after Performance Enhancement Training sessions suggesting the decrease in his blood pressure during the sessions.

The results show that Performance Enhancement Training, which in this case consisted of twenty-six sessions, was associated with positive changes in 
FIGURE 3. Pre- and post-response time scores collected from one participant and measured by TOVA continuous performance test on 04/09/98 and 08/12/98. Lower values indicate better performance

Response Time

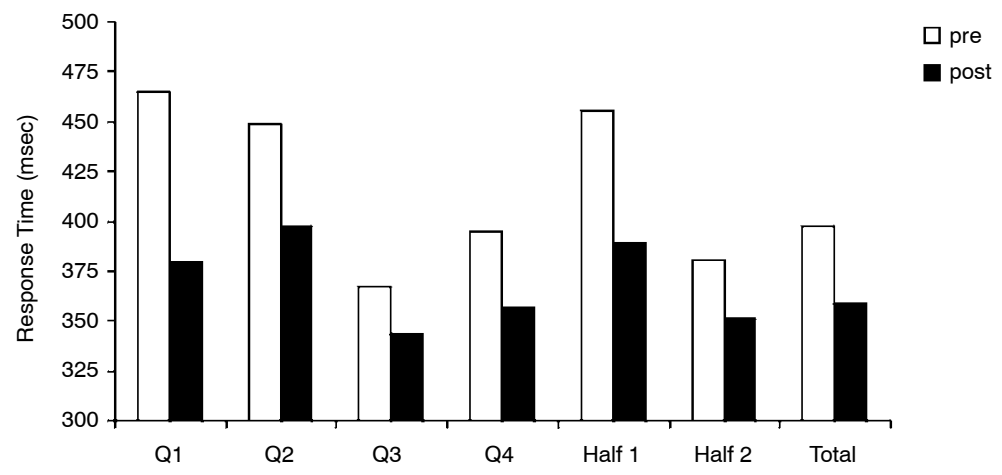

FIGURE 4. Pre- and post-response time variability scores collected from one participant and measured by TOVA continuous performance test on 04/09/98 and 08/12/98.

Response Time Variability

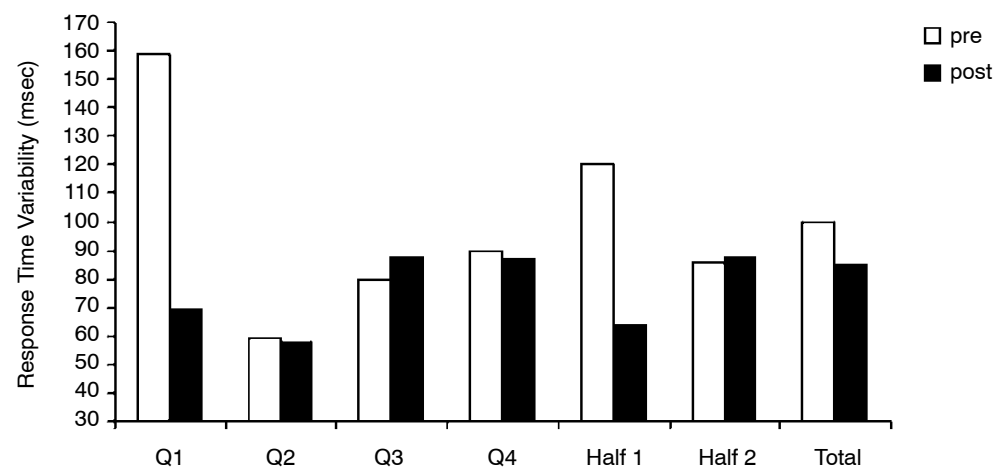

reaction time and reaction time variability measured by the TOVA. Training conducted over one electrode site (PZ) correlates with one complex or two different neurophysiological systems affecting blood pressure and attention.

The participant's Self-Assessment Stress Inventory scores indicated an improvement on the Social Life Scale dimension referring to accepting others 
opinions and becoming more interested in what others have to say. Also, his responses on the Work Scale dimension indicate that he became aware of the always-present tension and the constant rush during his job-related duties. During the initial interview the participant indicated that he was not aware of fight-and-flight response taking place in his body during his work-related activities. He did not think that his job-related activities could have contributed to his high blood pressure. As sessions progressed, he became more and more sensitive to the fight and flight response that occurred in his body as a result of a job related stress and emotional reactions triggered by those changes. He also became aware of his general and specific emotional states at every moment of his life.

In the post interview, the participant's introspective verbal report suggested a gradual increase in his level of self-awareness throughout the training. He stated that he realized how much his body reacted to the emergency situations related to his work duties. When he was in the fire truck responding to an emergency call, he realized how the presence of stress-related stimuli such as fire alarm sounds, speed of the vehicle, and flashing lights triggered psychophysiological reactions like perspiration, increase in respiration, increase in muscle tension and subjective experience of adrenaline rush (see Appendix). At one point, he came to realize, during one of the more difficult fires, that this job has become too demanding for his body. During one of the fires, he had a discussion with a young 25-year-old fireman, who according to the participant's description was the type of person fit for this job. He appeared to be filled with extra energy required to take care of the demand of the situation. The participant noticed that although he was still in a very good physical shape-perfect weight for his height, watching his diet, constantly exercising, and enjoying his work-he did not feel as that twenty-five-year-old felt. He realized that although he was still enjoying what he was doing, it was the time to move on. He took an administrative job in the New York Fire Department, which demanded different types of skills such as writing and being a spokesperson. He reported that this was something that he utterly enjoyed and was looking to excel at. He could also dedicate himself to learn more about computers and computer programming.

We hope that the outcome of our study provides findings that could contribute to the development of an integrative system as suggested by Peter Parks (1996), aimed to evaluate the acquisition of conscious control of neurophysiological variables. We believe that a double-feedback loop proposed in this study is an essential part of this system where increased self-awareness is associated with increased alpha production and increased alpha production is associated with further increased self-awareness. A self-realization of adverse stressors could be essential for a person to succeed in lowering his arousal and eliciting the relaxation response. Our results support our hypoth- 
esis that increased alpha production will assist individuals in the process of enhancing their self-awareness, and increased self-awareness will help them become aware of stressors that trigger undesirable sympathetic reactions. The aforementioned self-awareness process occurs in a particular attentional state that subjects usually describe as relaxed but alert. They report that as training progresses they are increasing their ability to maintain this state longer. We believe that what the participants refer to is a gradual improvement in their ability to sustain attention to internal physiological processes. It appears that this training generalizes to general enhancement of sustained attention to internal and external events and leads to a better performance on external attention tasks measured by continuous performance tests.

The therapeutic effects of elicitation of the relaxation response have traditionally been attributed to self-regulation of the sympathetic nervous system. Present research suggests that relaxation response affects cortical activation in anterior brain regions (Jacobs, Benson \& Freedman, 1996). The anterior cortical regions have been associated with emotional self-regulation via connection with subcortical structures such as the limbic system and hypothalamus (Nauta, 1971). These cortical structures are intimately involved in the sympathetically mediated fight-or-flight response. These studies suggest that the relaxation response might exert its initial effects through the self-regulation of activation in the frontal cortical and subcortical structures. We believe that the parietal lobe also plays an important role in mediating self-regulatory processes. Our future studies will be geared toward a better understanding of psychophysiological mechanisms mediating self-regulation.

\section{REFERENCES}

Benson, H., Shapiro, D., Tursky, B., \& Schwartz, G.E. (1971). Decreased systolic blood pressure through operant conditioning techniques in patients with essential hypertension. Science, 173, 740-741.

Benson, H. (1975). The relaxation response. New York: William Morrow and Company, Inc.

Crawford, H.J., \& Vasilescu, L.P. (1995). Differential EEG pattern activity of low and high sustained attention adults during decision-making task. Paper presented at Society for Psychophysiological Research, Toronto, Canada.

Fehmi, L.G., \& Fritz, G. (1980). Open Focus: The attentional foundation of health and well-being. Somatics, 2 (4), 24-30.

Green, E., \& Green, A. (1977). Beyond biofeedback. Ft. Wayne, IN: Knoll Publishing.

Greenberg L.M., \& Kindschi C.L. (1996) Test of Variables of Attention. Clinical Guide. Universal Attention Disorders, Inc.

Greenberg, L.M., \& Waldman, I.D. (1993). Developmental Normative Data on The Test of Variables of Attention (TOVA). Journal of Child and Adolescent Psychiatry, 34 (6), 1019-1030. 
Jacobs, G.D., Benson, H., \& Friedman, R. (1996). Topographic EEG mapping of the relaxation response. Biofeedback and Self-Regulation, 21( 2), 121-129.

Kamiya, J. (1969). Operant control of the EEG alpha rhythms and some of its reported effects on consciousness. In: Tart, C.T. (Ed.) Altered states of consciousness (p. 573). New York: Wiley and Sons.

Nauta, W. (1971). The problem of the frontal lobe: A reinterpretation. Journal of Psychiatric Research, 8, 167-187.

Nowles, D.P. \& Kamiya, J. (1970). The control of electroencephalographic alpha rhythms through auditory alpha feedback and associated mental activity. Psychophysiology, 6( 4), 476-484.

Norris, S.L., Lee, C.T., Cea, J. \& Burshteyn, D. (1998). Performance enhancement training effects on attention: A case study. Journal of Neurotherapy, 3 (1), 21-25.

Osterkamp, L., \& Press, A.N. (1983). Stress? Find your balance. (pp. 7-12). Lakewood, CO: Celestial Express.

Papillo, J.F., \& Shapiro, D. (1990). The cardiovascular system. In J.T. Cacioppo \& L.G. Tassinary (Eds.), Principles of psychophysiology: Physical, social, and inferential elements (pp. 456-512). Cambridge, England: Cambridge University Press.

Parks, Peter A. (1997). Psychophysiological self-awareness training: Integration of scientific and humanistic principles. Journal of Humanistic Psychology, 37 (2), 67-113.

Parks, Peter A. (1996). Psychophysiological self-awareness and self-regulation training: A databased assessment of eeg amplitude score and divergent thinking measures. Doctoral Dissertation.

Patel. (1977). Biofeedback-aided relaxation and meditation in the management of hypertension. Biofeedback and Self-Regulation, 2, 1-41.

Ray, W.J., \& Cole, H.W. (1985). EEG alpha activity reflects attentional demands, and beta activity reflects emotional and cognitive processes. Science, 228, 750-752.

Thatcher, R.W. (1999) Life-Span EEG normative database. In Manual, Description of Normative EEG Database.

Wallace R.K., \& Benson, H. (1972). The physiology of mediation. Scientific American, 84-90.

RECEIVED: $12 / 26 / 98$

REVISED: $03 / 30 / 00$

ACCEPTED: 05/08/00 


\section{APPENDIX}

In the spring of 1998, I participated in biofeedback assisted relaxation training ostensibly to manage hypertension. While the training has been successful toward that end, I have also learned a great deal about managing my physical and emotional states. I am a Lieutenant in the New York City Fire Department. My job subjects me to a great deal of situational stress, and I believed this contributed to my mild hypertension. When I was first exposed to biofeedback training, I quickly achieved a relaxed state in an experimental environment. However, I was not confident that the results would generalize out to my work environment. I commented, "I'll be impressed if I can learn to relax while racing up First Avenue in the front seat of a fire truck." The results are beyond my greatest expectations.

Within the first few training sessions I could successfully raise the level of my alpha brain wave readings. I achieved this by becoming aware of subtle states of tension in different muscle groups. I started by placing my feet flat on the floor and consciously relaxing the muscles in my lower legs, then my thighs. As the training progressed I was able to successfully relax the muscle group in my abdomen, upper and lower back and facial muscles. When I let go of tension in any particular area of my body, I saw almost instantaneous reactions in the instruments monitoring my brain waves. I quickly became proficient at duplicating the physical state that produced the desired brain wave pattern.

The biofeedback experiment I participated in required that I maintain a state of attention in addition to one of relaxation. This helped me to apply the training in my work environment. While at work, I perform administrative work until an emergency response is required. I am alerted to an emergency by an electronic tone that occurs simultaneously with computer-generated printout. The printout describes the emergency and gives its location. This tone initiates a series of actions that are ritual-like in their repetitiveness. I slide down a pole, don fire fighting clothing, take the printout of the response information and position myself in the front, passenger seat of the fire apparatus. During the response, I must monitor radio transmissions, assist the driver in negotiating through traffic, and prepare my course of action based on the information I have and Fire Department procedures. All of this requires that I maintain a state of attention.

I was able to use the repetitiveness of my emergency responses to create a ritual of relaxation. Once I took my position in the front of the fire apparatus, I duplicated some of the postures I learned in the experimental setting. I placed my feet flat on the floor, I focused attention to muscle groups that would usually become tense during a response, and I stayed aware of my breathing. In short, I duplicated the physical state I was learning in the experimental environment. I was easily able to accomplish this while attend- 
ing to my other responsibilities. Within a short period of time, I incorporated this behavior into my response routine; it became almost automatic. The tone alert that I used to associate with tension now became a trigger for physical relaxation. Ironically, I became more proficient at producing a relaxed state when I was confronted with the very conditions that were contributing to increased stress. In the course of everyday life, I am not always focused on my physiology. But now, in my work environment, a tone alert triggers a routine of learned relaxation.

In addition to a newfound awareness of my physiology, my experience with biofeedback assisted relaxation training has improved my emotional state. When I find myself in a state of emotional discomfort, duplicating my learned state of relaxation usually improves my state of mind. While this is a more subjective state, and thus difficult to describe, I can confidently report a generally improved state of mind since I have completed the training. As a result of the training, I have become proficient at detaching from an anxious, or otherwise uncomfortable, emotional state. It is as if I am capable of observing my own experience in a detached ego state. I am more aware of the relationship that exists between emotional and physical states. I am able to scrutinize my physical state and choose a more comfortable emotional state. If an emotion is a physical state to which we affix a label, I am now more proficient at choosing a comfortable label. 